\title{
GLUT3 expression in cystic change induced by hypoxia in pituitary adenomas
}

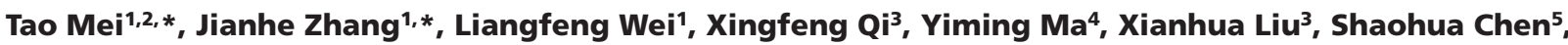 \\ Songyuan $\mathrm{Li}^{1}$, Jianwu $\mathrm{Wu}^{1}$ and Shousen Wang ${ }^{1}$
}

'Department of Neurosurgery, Fuzhou General Hospital, Fuzhou, China

${ }^{2}$ Fuzong Clinical Medical College of Fujian Medical University, Fuzhou, China

${ }^{3}$ Department of Pathology, Fuzhou General Hospital, Fuzhou, China

${ }^{4}$ Department of Neurosurgery, Liuzhou General Hospital, Liuzhou, China

${ }^{5}$ Department of Pathology, The Second Affiliated Hospital of Fujian Medical University, Quanzhou, China

Correspondence should be addressed to S Wang: wshsen@126.com

*(T Mei and J Zhang contributed equally to this work)

\begin{abstract}
Tumor cells require large amounts of energy to sustain growth. Through the mediated transport of glucose transporters, the uptake and utilization of glucose by tumor cells are significantly enhanced in the hypoxic microenvironment. Pituitary adenomas are benign tumors with high-energy metabolisms. We aimed to investigate the role of expression of glucose transporter 3 (GLUT3) and glucose transporter 1 (GLUT1) in pituitary adenomas, including effects on size, cystic change and hormone type. Pituitary adenomas from 203 patients were collected from January 2013 to April 2017, and immunohistochemical analysis was used to detect the expression of GLUT3 and GLUT1 in tumor specimens. GLUT3-positive expression in the cystic change group was higher than that in the non-cystic change group $(P=0.018)$. Proportions of GLUT3-positive staining of microadenomas, macroadenomas, and giant adenomas were 22.7 (5/22), 50.4 (66/131) and $54.0 \%(27 / 50)$, respectively $(P=0.022)$. In cases of prolactin adenoma, GLUT3-positive staining was predominant in cell membranes $(P=0.000006)$, while in cases of folliclestimulating hormone or luteotropic hormone adenoma, we found mainly paranuclear dot-like GLUT3 staining $(P=0.025)$. In other hormonal adenomas, GLUT3 was only partially expressed, and the intensity of cell membrane or paranuclear punctate staining was weak. In contrast to GLUT3, GLUT1 expression was not associated with pituitary adenomas. Thus, our results indicate that the expression of GLUT3 in pituitary adenomas is closely related to cystic change and hormonal type. This study is the first to report a unique paranuclear dot-like GLUT3 staining pattern in pituitary adenomas.
\end{abstract}
Key Words
- GLUT3
- GLUT1
- HIF-1 $\alpha$
- pituitary adenomas
- immunohistochemistry

\section{Introduction}

Pituitary adenomas (PA) are among the most common intracranial tumors, accounting for $10-15 \%$ of primary intracranial tumors (1). It has been confirmed by positron emission tomography and tumor cell culture experiments that PA tumor cells have high metabolic characteristics (2). Other studies have suggested that angiogenesis is not pronounced in PA, and therefore, the low blood supply and high metabolisms of PA cells make tumor tissues readily susceptible to ischemia and hypoxia (3). Because glucose is the main source of energy for tumor cells, study of the glucose metabolism in PA will improve our understanding of the biobehavioral mechanisms of PA cell energy metabolism.

While glucose is the main energy source of the human brain, neurons cannot synthesize or store glucose (4). 
Therefore, glucose uptake is necessary for the maintenance of neuronal function. Thus far, 14 members of the glucose transporter (GLUT) family have been discovered, of which GLUT1 and GLUT3 play major roles in glucose uptake in the brain (4). GLUT1 is the most abundant glucose transporter in the brain. The uptake of glucose in the brain is related to the expression level of GLUT1 in microvessels. GLUT3 is the second most abundant glucose transporter in the brain, and its transport capacity is seven times higher than that of GLUT1 (5). It exists in axons and dendrites, and its density and distribution are related to local glucose demand (5). This distribution may change under pathological conditions. In hypoxic ischemic encephalopathy, neurons may upregulate the expression of GLUTs, especially GLUT3, thereby increasing glucose uptake in order to increase tolerance to ischemia and hypoxia (6).

There have been many studies on the molecular mechanisms of GLUT-mediated tumor energy metabolism. The expression and distribution of GLUTs are regulated by various signaling molecules and pathways, including the hypoxia-inducible factor-1 (HIF-1), phosphoinositide 3-kinase/protein kinase B (PI3K/Akt), AMP-activated protein kinase/mammalian target of rapamycin 1 (AMPK/ mTOR1) and tumor suppressor gene p53 signaling pathways. Among these, the HIF-1 pathway plays a major role in ischemia and hypoxia (7).

HIF-1 $\alpha$ not only plays an important role in normal glucose metabolism but also maintains the local environmental oxygen homeostasis in hypoxic environments. It is also the most important regulator of GLUT1 and GLUT3 (8). In the absence of oxygen, HIF$1 \alpha$ stimulates multiple genes that mediate glycolysis and promote the Warburg effect. These genes, including GLUT1 and GLUT3, possess promoters with hypoxic response elements, to which HIF- $1 \alpha$ complexes bind to initiate the expression of GLUT genes (9).

Tumor cells require large amounts of energy to maintain proliferation, but because angiogenesis is lacking in PA, tumor cells must switch their metabolic pattern from primarily glycolysis of glucose to adapt to a hypoxic microenvironment. Tumors enhance their energy metabolism by strengthening the anaerobic glycolysis pathway through the 'Warburg effect', which requires more glucose be imported into the cell, resulting in significantly enhanced glucose uptake and utilization by tumor cells (10). Thus, PA cells may upregulate GLUT expression to meet these energy requirements for rapid growth, making GLUTs potential candidates for targeted therapy against PA. The purpose of this study was to determine whether there is a link between GLUT expression and growth, cystic change and invasive behavior in PA, thereby laying a foundation for improved understanding of the energy metabolism mechanisms of PA and providing a potential basis for new avenues of treatment for PA in the future.

\section{Materials and methods}

\section{Patients}

A total of 203 surgically resected PA tumor samples that were pathologically confirmed were collected from January 2013 to April 2017 at the Department of Neurosurgery of Fuzhou General Hospital. Complete medical records, images and pathological specimens were obtained (in case of the prolactinoma samples, surgical therapy was performed on patients with dopamine agonist intolerance or resistance or patients exhibiting normal serum prolactin and with visual defects and headaches). Patients provided written informed consent for tissue and clinical data collection. This study was approved by the ethics review board of Fuzhou General Hospital.

\section{Immunohistochemical analysis}

Rabbit anti-human monoclonal GLUT1 and GLUT3 antibodies were purchased from Abcam and were used at working dilutions of $1: 250$ and $1: 400$, respectively (Table 1). EliVision Super/HRP, phosphate-buffered saline (PBS), sodium citrate buffer, neutral gum and hematoxylin were all purchased from Fuzhou Maixin Co. (Fuzhou, China). Xylene, ethanol, 30\% $\mathrm{H}_{2} \mathrm{O}_{2}$ and distilled water were provided by the Central Laboratory of Fuzhou General Hospital. The pathology department of Fuzhou General Hospital had performed immunohistochemical staining of the tumor tissues for Ki67.

EliVision immunohistochemistry was performed using a two-step method, according to the manufacturer's instructions. Briefly, $3 \mu \mathrm{m}$ sections were deparaffinized in xylene, rehydrated with decreasing concentrations of alcohol and microwaved in $10 \mathrm{mmol} / \mathrm{L}$ citrate buffer $(\mathrm{pH}$ 6.0) for $15 \mathrm{~min}$. Endogenous peroxidase was inhibited by incubation for $10 \mathrm{~min}$ in $3 \% \mathrm{H}_{2} \mathrm{O}_{2}$ in methanol. Sections were then incubated with $2 \%$ normal goat serum in $1 \%$ bovine serum albumin in PBS for $30 \mathrm{~min}$ at room temperature $\left(25^{\circ} \mathrm{C}\right)$, washed in PBS and incubated with GLUT3 and GLUT1 antibodies for $60 \mathrm{~min}$ at room temperature or overnight at $4^{\circ} \mathrm{C}$. Next, sections were incubated with an enhancer at $37^{\circ} \mathrm{C}$ for $20 \mathrm{~min}$, followed by a 30-min incubation with the secondary antibody at $37^{\circ} \mathrm{C}$. 
Table 1 Antibodies used in this study.

\begin{tabular}{ll}
\hline Antibody & Protein localization \\
\cline { 1 - 1 } GLUT1 & Plasma membrane and cytoplasm \\
GLUT3 & Plasma membrane \\
HIF-1 $\alpha$ & Nucleus and cytoplasm \\
\hline
\end{tabular}

Clone/species
Polyclonal/rabbit
Polyclonal/rabbit
Polyclonal/mouse

Positive control
Renal cell carcinoma lysate; plasma membrane of
human erythrocytes
Placenta
Human gastric cancer tissue

Finally, sections were stained with DAB, counterstained with hematoxylin, dehydrated and mounted.

Mouse anti-human monoclonal HIF- $1 \alpha$ antibody was purchased from Abcam and used at a working dilution of 1:500. EliVision immunohistochemistry was performed using a two-step method, and sections were stained following the steps described earlier.

Stained specimens were viewed using a CX41 microscope (Olympus) and imaged using Image Pro Plus 6.0 (Media Cybernetics, Rockville, MD, USA). Positive controls (Table 1) were used according to manufacturer recommendations for the primary antibody protocol, and internal microlymphocytes or vascular endothelial cells were also used as internal positive controls. PBS instead of primary antibody was used as a negative control. Expression of GLUT1 is predominantly membranous or cytoplasmic, while that of GLUT 3 is mainly membranous (11). The expression of HIF- $1 \alpha$ is predominantly nuclear or cytoplasmic. The degree of expression was assessed based on staining intensity scores of $0,1,2$ and 3, indicating no staining, mild staining, moderate staining and strong staining, respectively. In addition, we performed staining area integration selection under high magnification (200x), in which five high-powered fields were randomly selected for each section, and 100 cells were counted in each field for a total of 500 cells. Scores of 0, 1, 2 and 3 were assigned based on proportions of stained cells of $<10,10-25,25-50$ and $>50 \%$, respectively. The total protein expression score in the tumor tissue from each patient was calculated as the sum of these two scores, with a total score $>2$ indicating positive expression and $\leq 2$ indicating negative expression (12).

\section{Statistical analysis}

All data were analyzed with SPSS Statistics for Windows, version 23 (SPSS Inc.). Categorical variables were expressed in terms of absolute frequencies and percentages. Mean values were used to express continuous variables. Data were analyzed by the $\chi^{2}$ test for statistical difference. A $P$ value $<0.05$ was considered statistically significant. Bonferroni correction was used for multiple comparisons

$\begin{array}{lr}\text { https://ec.bioscientifica.com } & \text { ○ } 2018 \text { The authors } \\ \text { https://doi.org/10.1530/EC-18-0444 } & \text { Published by Bioscientifica Ltd }\end{array}$

and the $P$ values were compared against $\alpha /$ number of comparisons instead of $\alpha=0.05$.

\section{Results}

\section{GLUT1 expression in PA cases}

The patient cohort consisted of 116 males and 87 females, with a male to female ratio of 1.33:1; patient ages ranged from 18 to 79 years, with an average age of $47.50 \pm 13.39$ years. According to immunohistochemistry (13), there were 49 cases of prolactin (PRL), 11 cases of growth hormone $(\mathrm{GH}), 33$ cases of multiple hormone, 42 cases of follicle-stimulating hormone or luteotropic hormone (FSH/LH), 7 cases of thyroid-stimulating hormone (TSH), 8 cases of adrenocorticotropic hormone (ACTH) and 53 cases of null-cell adenoma (Table 2).

Positive expression of GLUT1 in the PA samples from our cohort mainly presented as cytoplasmic staining (Fig. 1), with a positive rate of $86.2 \%(175 / 203)$ among all cases. We found no differences in expression among subgroups based on the type of PA. Two cases of PRL adenoma were weakly positive for GLUT1 cell membrane staining.

\section{Relationship between GLUT3 expression and age, Knosp score and Ki-67}

Expression of GLUT3 presented as mainly membranous or paranuclear dot-like staining in PA sections (Figs 2, 3 and 4). The proportion of GLUT3-positive cells was

Table 2 Classification of hormone types in 203 patients with pituitary adenoma.

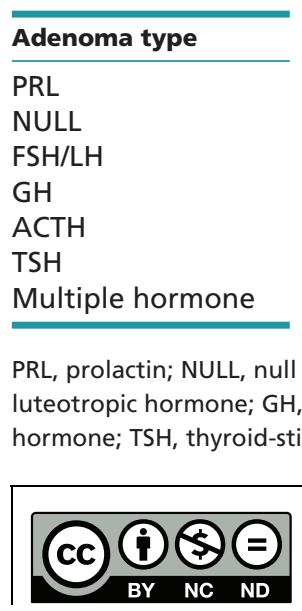

$\begin{array}{r}\hline \boldsymbol{n}(\%) \\ \hline 49(24.1) \\ 53(26.1) \\ 42(20.7) \\ 11(5.4) \\ 8(3.9) \\ 7(3.5) \\ 33(16.3) \\ \hline\end{array}$

\begin{tabular}{c}
\hline Male \\
\hline 24 \\
27 \\
29 \\
7 \\
4 \\
4 \\
21 \\
\hline
\end{tabular}

\begin{tabular}{c}
\hline Female \\
\hline 25 \\
26 \\
13 \\
4 \\
4 \\
3 \\
12 \\
\hline
\end{tabular}

null cell; FHS/LH, follicle-stimulating hormone/ luteotropic hormone; $\mathrm{GH}$, growth hormone; $\mathrm{ACTH}$, adrenocorticotropic hormone; TSH, thyroid-stimulating hormone.
This work is licensed under a Creative Commons Attribution-NonCommercial-NoDerivatives 4.0 International License. 


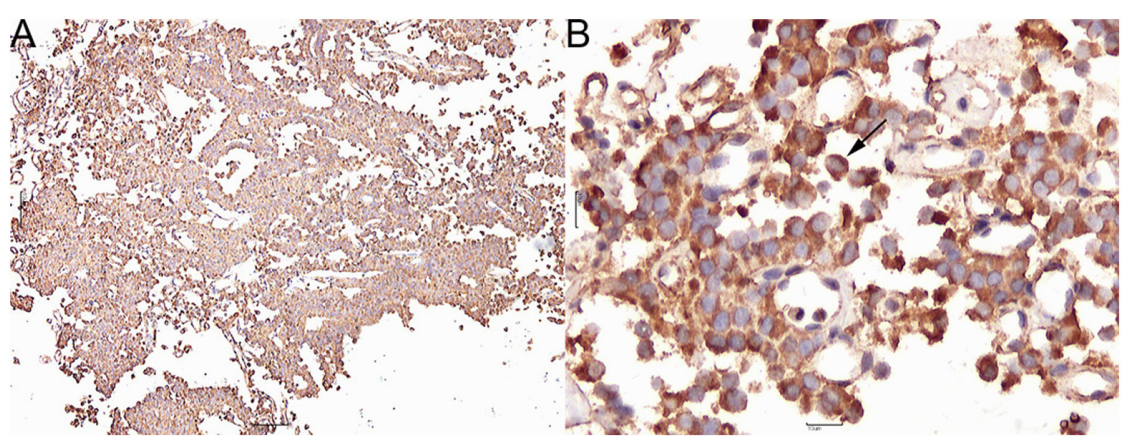

\section{Figure 1}

GLUT1 cytoplasmic immunostaining (black arrow) in pituitary adenoma cells (A, 40x; B, 200x).
$46.6(54 / 116)$ in males and $50.6(44 / 87)$ in females, with rates of $49.0(73 / 149)$ and $46.3 \%(25 / 54)$ in patients less than or over 60 years of age, respectively. Within Knosp score ranges of 0-2 and 3-4, GLUT3 expression was observed in 43.6\% (48/110) and 53.8\% (50/93) of cases, respectively. Furthermore, the proportions of GLUT3positive cases with Ki-67 grades of $<3$ or $\geq 3$ were 52.0 (77/148) and 50.9\% (28/55), respectively. However, none of these differences between groups were statistically significant (all $P>0.05$, Table 3 ).
Relationship between GLUT3 expression and cystic change, hormone type and tumor size

The cystic changes in PAs are shown in Fig. 5. We found that rates of GLUT3-positive expression were higher in the cystic change degeneration group compared to those in the non-cystic change group $\left(\chi^{2}=5.941\right.$, $P=0.018)$, with rates of $54.5(72 / 132)$ and $36.6 \%(26 / 71)$, respectively. There were also significant differences in GLUT3 expression among microadenomas (<10 mm),

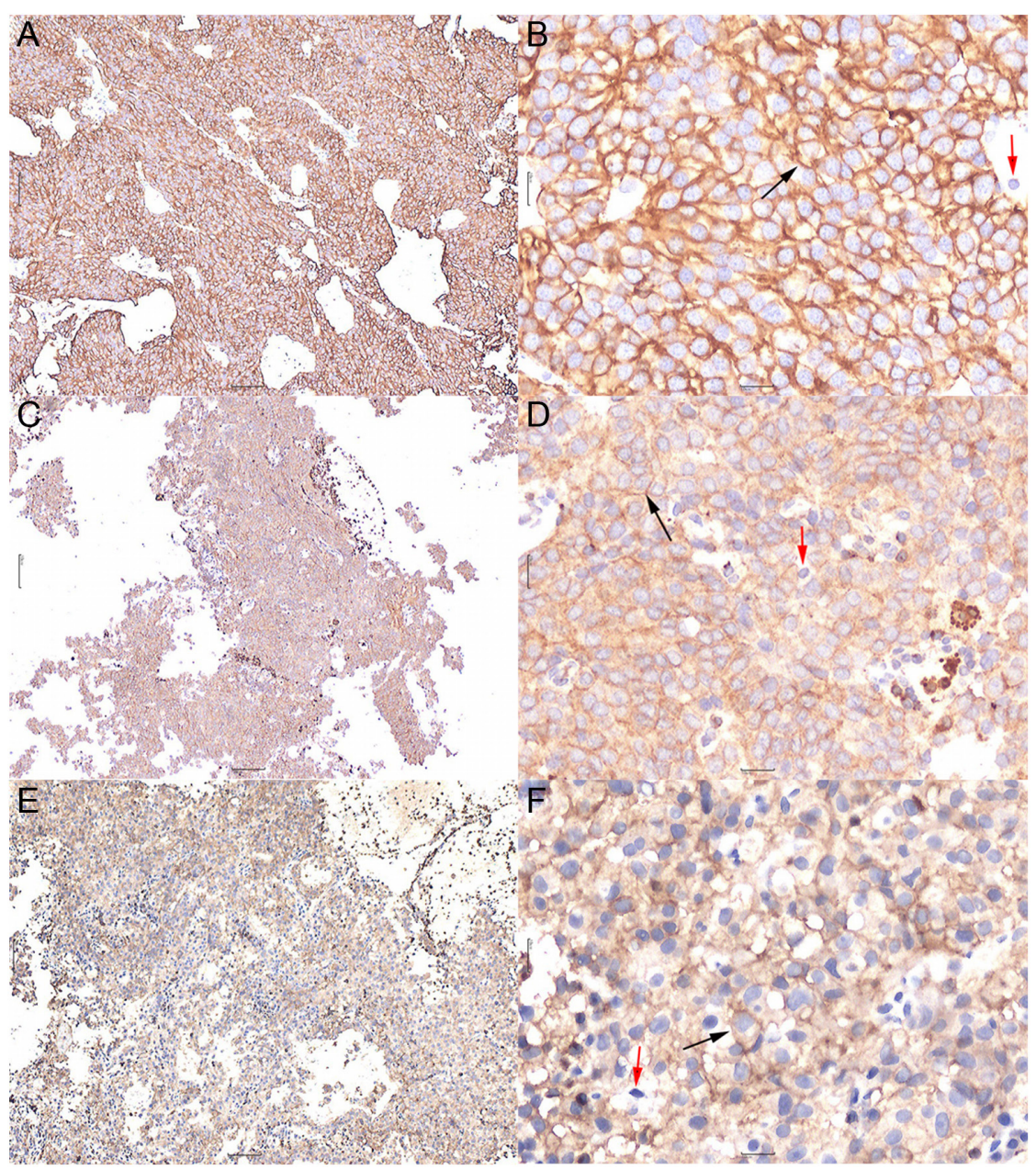

Figure 2

GLUT3 membrane immunostaining in pituitary adenoma cells. ( $A$ and $B$ ) High GLUT3 staining (A, 40x; B, 200x). (C and D) Moderate GLUT3 staining (C, 40x; D, 200x). (E and F) Low GLUT3 staining $(E, 40 x ; F, 200 x)$. Membrane-positive staining (black arrows) is evident in tumor cells, but lymphocytes are not stained (red arrows). https://ec.bioscientifica.com https://doi.org/10.1530/EC-18-0444 (c) 2018 The authors Published by Bioscientifica Ltd

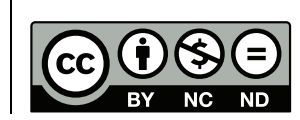

This work is licensed under a Creative Commons Attribution-NonCommercial-NoDerivatives 4.0 International License. 


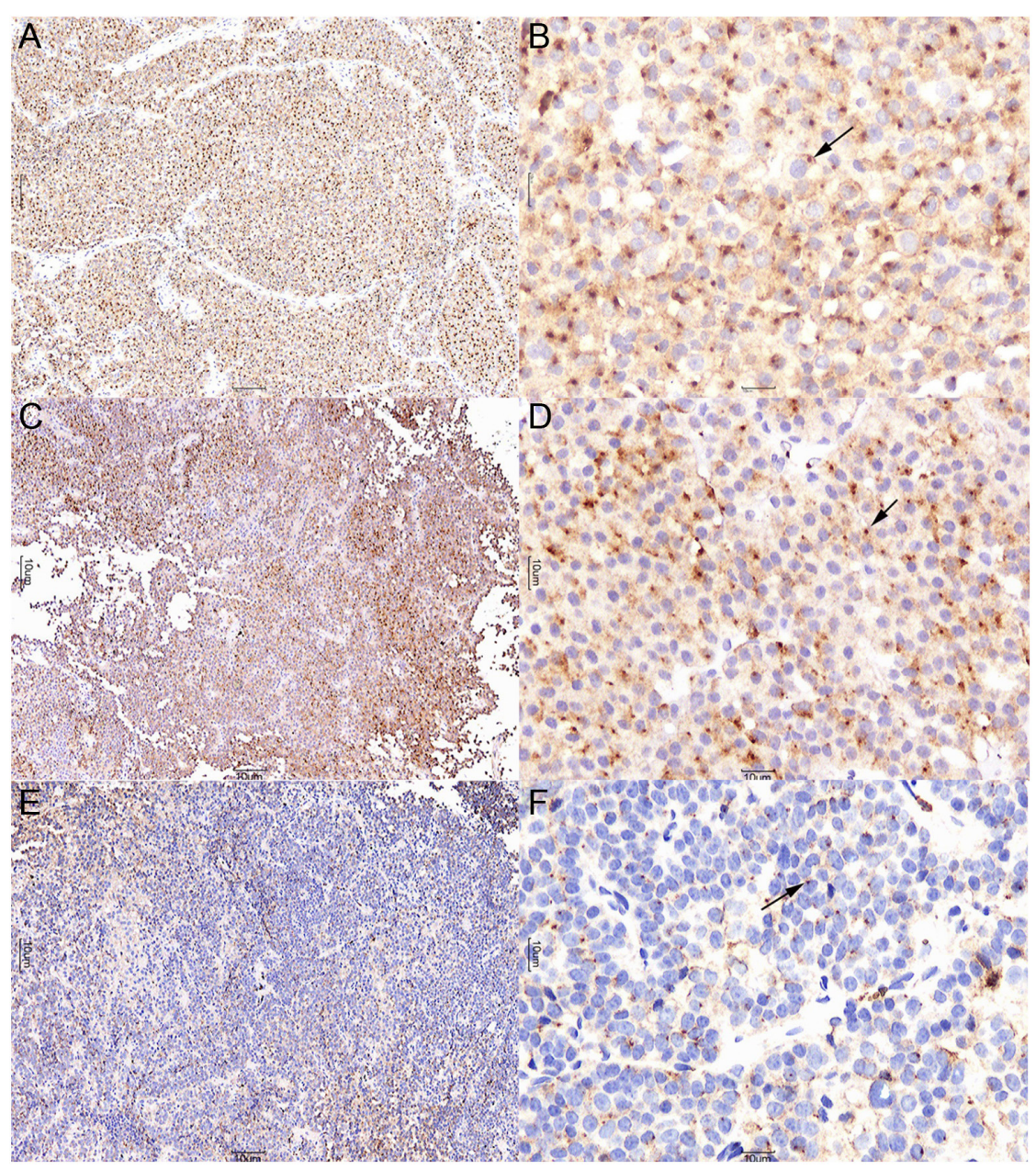

\section{Figure 3}

GLUT3 paranuclear dot-like immunostaining in pituitary adenoma cells (black arrows). (A and $B$ ) High GLUT3 staining (A, 40x; $B, 200 x)$. (C and D) Moderate GLUT3 staining (C, 40x; D, 200x). (E and F) Low GLUT3 staining ( $E, 40 x ; F, 200 x)$. macroadenomas ( $\geq 10 \mathrm{~mm})$ and giant adenomas $(\geq 40 \mathrm{~mm})$, with proportions of 22.7 (5/22), 50.4 (66/131) and 54.0\% $(27 / 50)$, respectively $\left(\chi^{2}=7.622, P=0.022\right.$; Table 3$)$. Based on pairwise comparisons, we found that there was a statistically significant difference in expression between microadenomas and giant adenomas (Bonferroni-corrected $P=0.006, \alpha / 3=0.0167)$, but no statistically significant difference in expression between macroadenomas and microadenomas or between macroadenomas and giant adenomas (Bonferroni-corrected $P>0.0167, \alpha / 3=0.0167$ ).

\section{GLUT3 expression among different hormone types of PA}

Since positive expression of GLUT3 appeared as membrane and paranuclear dot-like staining patterns, we next evaluated differences in expression between these two staining patterns with regard to adenoma type. We found statistically significant differences in GLUT3-positive membrane staining, with rates of $61.2 \%$ in PRL (30/49), $26.4 \%$ in null cell (14/53), 14.3\% in FSH/LH (6/42), 36.4\%

\begin{tabular}{lr}
\hline https://ec.bioscientifica.com & ○ 2018 The authors \\
https://doi.org/10.1530/EC-18-0444 & Published by Bioscientifica Ltd
\end{tabular}

in GH (4/11), 25.5\% in ACTH (2/8), 14.3\% in TSH (1/7) and $12.1 \%$ in multiple hormone (4/33) adenoma cases in our cohort $\left(\chi^{2}=34.134, P=0.000006\right)$. Based on pairwise comparisons, we found that GLUT3-positive membrane staining was more prevalent in PRL adenomas than in cell null (Bonferroni-corrected $P=0.0004, \alpha / 21=0.002$ ), FSH/LH (Bonferroni-corrected $P=0.000005, \alpha / 21=0.002$ ) and multiple hormone adenomas (Bonferroni-corrected $P=0.00001, \alpha / 21=0.002)$. There were no other statistically significant differences among other pairwise comparisons (Bonferroni-corrected $P>0.002, \alpha / 21=0.002$ ).

We also found significant differences in GLUT3positive paranuclear dot-like staining, with rates of $16.3 \%$ in PRL (8/49), 28.3\% in null cell (15/53), 47.6\% in FSH/LH (20/42), 9.1\% in GH (1/11), 25.5\% in ACTH (2/8), 14.3\% in TSH (1/7) and $24.2 \%$ in multiple hormone (8/33) adenoma cases in our cohort $\left(\chi^{2}=14.413, P=0.025\right)$. Based on pairwise comparisons, we found that the prevalence of GLUT3-positive paranuclear dot-like staining in cases of FSH/LH adenoma was higher than that found in cases of PRL adenoma (Bonferroni-corrected $P=0.001$, 


\begin{tabular}{l|l|l|l|} 
Endocrine & T Mei et al. & $\begin{array}{l}\text { GLUT3 expression in pituitary } \\
\text { adenomas }\end{array}$ & $\mathbf{1 5 2 3}$
\end{tabular}

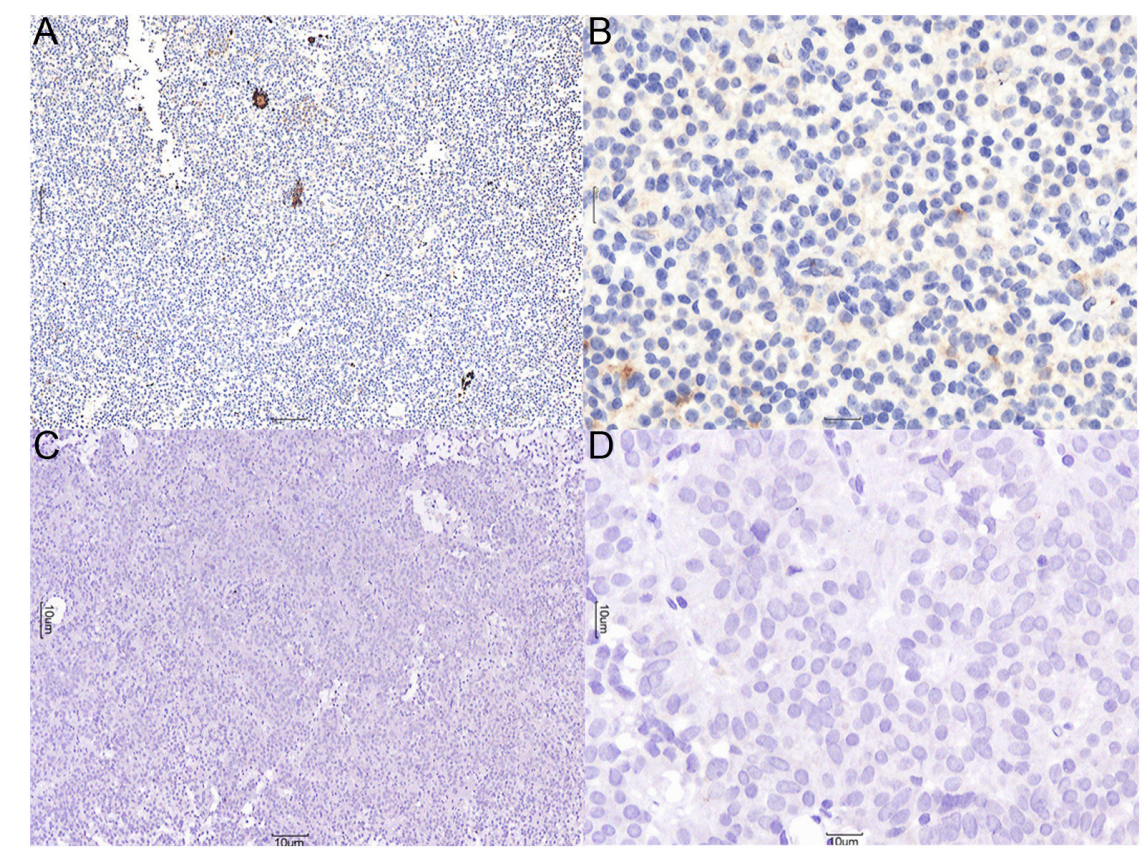

Figure 4

GLUT3-negative immunostaining in pituitary adenoma cells (A, 40x; $B, 200 x)$ and negative controls (C, 40x; D, 200x). $\alpha / 21=0.002$ ). No statistically significant differences were found among other pairwise comparisons (Bonferronicorrected $P>0.002, \alpha / 21=0.002$; Tables 4 and 5).

\section{HIF-1 $\alpha$ expression in PA}

In a subset of cases $(n=50)$ derived from our original sample, we also investigated HIF- $1 \alpha$ staining to identify differences between cystic change and non-cystic change staining patterns. This subset included 25 males and 25 females, with a male-to-female ratio of $1: 1$; patients were aged from 25 to 72 years, with an average age of $51.10 \pm 12.10$ years.

These 50 patients were divided into 30 cases of cystic change and 20 cases of non-cystic change according to preoperative MRI and intraoperative findings. Among the 50 tumor specimens, 46 showed varying degrees of expression of HIF- $1 \alpha$ in the nucleus (Fig. 6) and 4 showed no expression of HIF- $1 \alpha$, indicating that PAs generally exhibited HIF- $1 \alpha$ expression. According to the total scores of protein expression in tumor tissues, the positive expression rate of HIF- $1 \alpha$ in the cystic change group

Table 3 Clinicopathological characteristics of GLUT3-positive and GLUT3-negative groups.

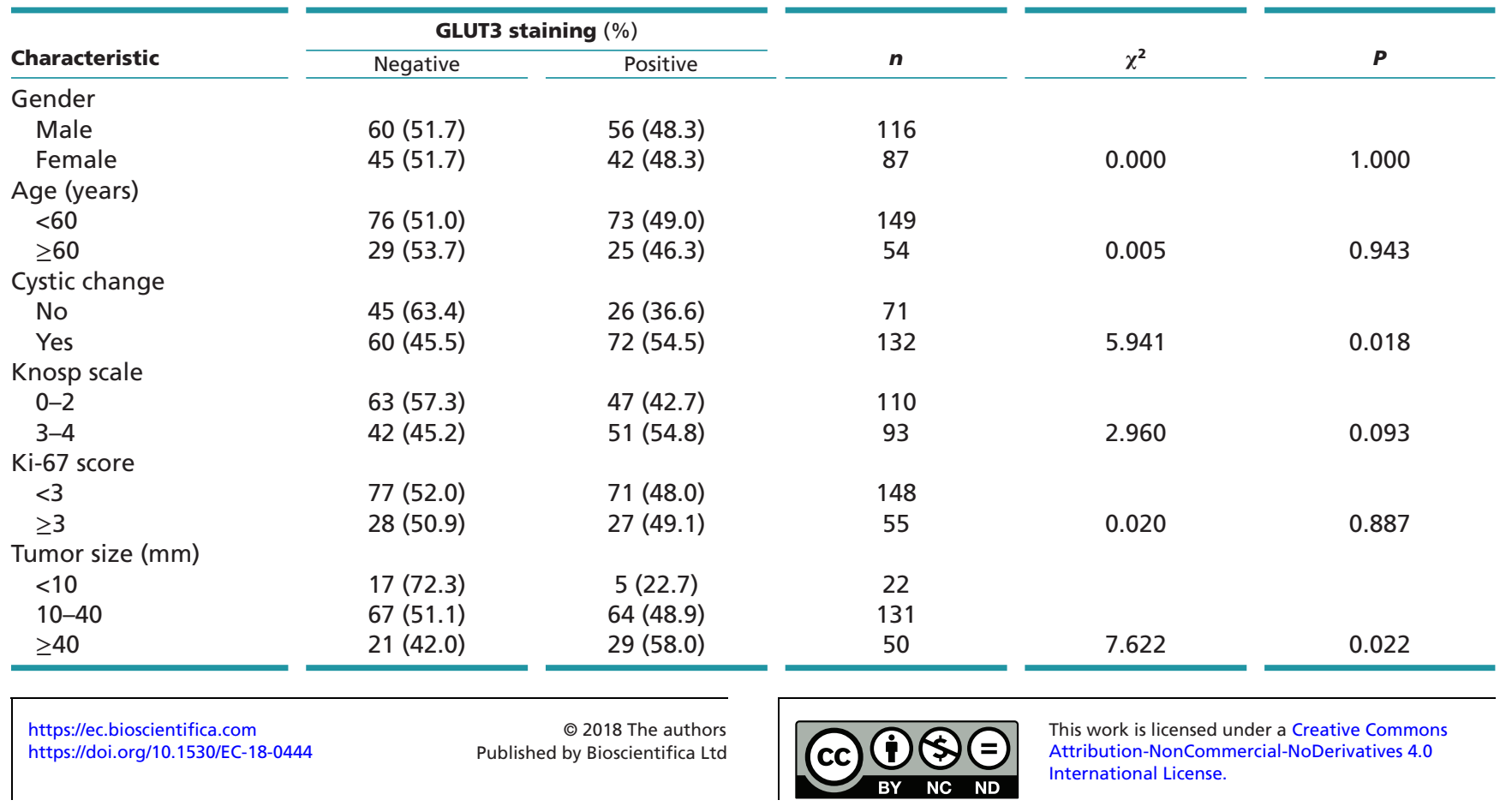




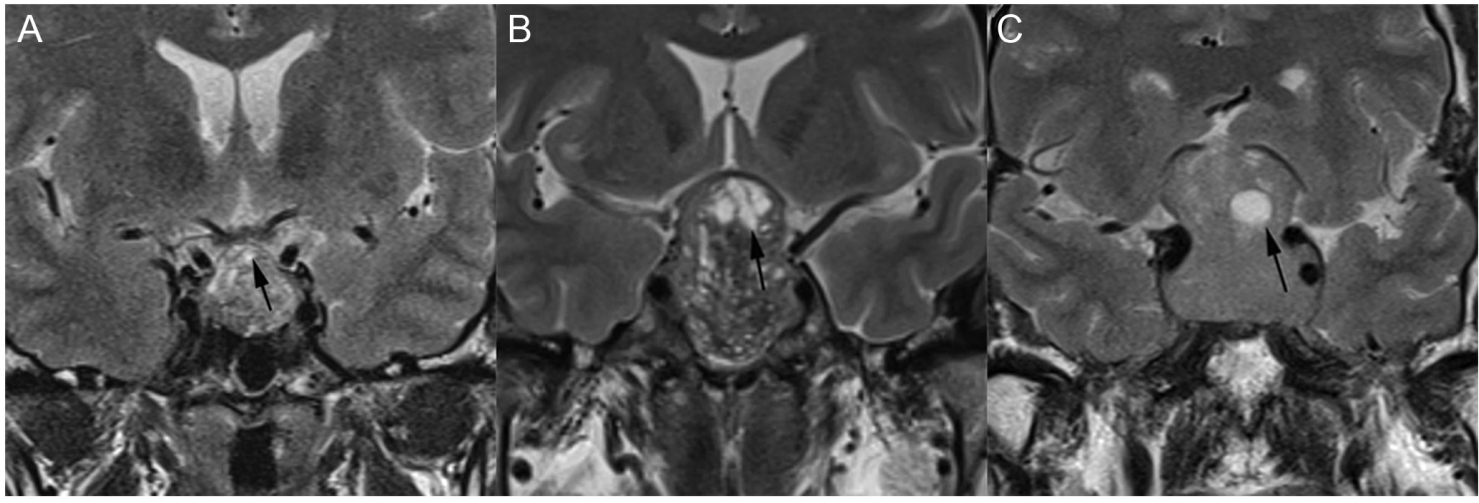

\section{Figure 5}

Types of cystic lesions in pituitary adenomas (black arrows). (A) Presence of scattered, small cystic lesions (GLUT3 paranuclear dot-like immunostaining shown in Fig. 3D). (B) Some scattered, small cystic lesions have merged into larger cystic lesions (GLUT3 membrane immunostaining shown in Fig. 2B). (C) Single, large cystic lesion (GLUT3 membrane immunostaining shown in Fig. 2D).

was $64.3 \%(18 / 28)$, which was significantly higher than the rate of $31.8 \%(7 / 22)$ in the non-cystic change group $\left(\chi^{2}=5.195, P=0.023\right.$; Table 6).

\section{Discussion}

GLUTs have been widely studied in many tumor types; however, this is the first study to investigate GLUTs in PA. We discovered a unique paranuclear dot-like staining pattern of GLUT3, which has not been previously described in other tumor types. Furthermore, there was a difference in GLUT3 membrane and paranuclear dot-like expression in PAs of different hormone types, as well as statistically significant differences in GLUT3 expression among different tumor sizes, hormone types and cystic change statuses. GLUT3 may therefore play an important role in the process of ischemia-hypoxia and secondary cystic change in PA, with differences in PA metabolism among different hormone types. In contrast, GLUT1 was mainly expressed in the cytoplasm of PA cells, and there were no differences in expression among subgroups; therefore, we did not further investigate or consider the expression of GLUT1 as a membrane protein for glucose transport in the context of PA.

GLUTs are sugar transporter membrane proteins that are indispensable for cell energy metabolism. Glucose molecules can be transported through the lipid bilayer of the cell membrane for uptake and utilization of glucose (7). Tumor cells require more energy than non-tumor cells to sustain growth; however, due to a limited oxygen supply, tumor cells must convert their metabolic patterns to adapt to the corresponding microenvironment. Tumor cells can accelerate anaerobic glycolysis through the Warburg effect, which requires additional glucose transport into the cell. Through the mediated transport of GLUTs, the uptake and utilization of glucose by tumor cells can be significantly enhanced. Therefore, GLUTs tend to be upregulated to meet the energy needs of rapid tumor growth (10).

Our study showed that only four cases of PA were negative for HIF-1 $\alpha$ expression, with the rest showing various degrees of expression of HIF-1 $\alpha$. Our study also showed a statistically significant difference in the

Table 4 GLUT3-positive and GLUT3-negative membrane staining based on adenoma type.

\begin{tabular}{|c|c|c|c|c|c|}
\hline \multirow[b]{2}{*}{ Adenoma type } & \multicolumn{2}{|c|}{ Membrane localization (\%) } & \multirow[b]{2}{*}{$n$} & \multirow[b]{2}{*}{$\chi^{2}$} & \multirow[b]{2}{*}{$\boldsymbol{P}$} \\
\hline & Yes & No & & & \\
\hline PRL & $30(61.2)$ & $19(38.8)$ & 49 & & \\
\hline NULL & $14(26.4)$ & $39(73.6)$ & 53 & & \\
\hline FSH/LH & $6(14.3)$ & $36(85.7)$ & 42 & & \\
\hline $\mathrm{GH}$ & $4(36.4)$ & $7(63.6)$ & 11 & & \\
\hline ACTH & $2(25.5)$ & $6(75.5)$ & 8 & & \\
\hline TSH & $1(14.3)$ & $6(85.7)$ & 7 & & \\
\hline Multiple hormone & $4(12.1)$ & $29(87.9)$ & 33 & 34.134 & 0.000006 \\
\hline
\end{tabular}

ACTH, adrenocorticotropic hormone; FHS/LH, follicle-stimulating hormone/luteotropic hormone; GH, growth hormone; NULL, null cell; PRL, prolactin; TSH, thyroid-stimulating hormone.

$$
\begin{aligned}
& \text { https://ec.bioscientifica.com } \\
& \text { https://doi.org/10.1530/EC-18-0444 } 2018 \text { The authors } \\
& \text { Published by Bioscientifica Ltd }
\end{aligned}
$$


Table 5 GLUT3-positive and GLUT3-negative paranuclear dot-like staining based on adenoma type.

\begin{tabular}{|c|c|c|c|c|c|}
\hline \multirow[b]{2}{*}{ Adenoma type } & \multicolumn{2}{|c|}{$\begin{array}{c}\text { Paranuclear dot-like } \\
\text { staining }(\%)\end{array}$} & \multirow[b]{2}{*}{$n$} & \multirow[b]{2}{*}{$\chi^{2}$} & \multirow[b]{2}{*}{$\boldsymbol{P}$} \\
\hline & Yes & No & & & \\
\hline PRL & $8(16.3)$ & $41(83.7)$ & 49 & & \\
\hline NULL & $15(28.3)$ & $38(71.7)$ & 53 & & \\
\hline FSH/LH & $20(47.6)$ & $22(52.4)$ & 42 & & \\
\hline $\mathrm{GH}$ & $1(9.1)$ & $10(90.9)$ & 11 & & \\
\hline АСТH & $2(25.0)$ & $6(75.0)$ & 8 & & \\
\hline TSH & $1(14.3)$ & $6(85.7)$ & 7 & & \\
\hline $\begin{array}{l}\text { Multiple } \\
\text { hormone }\end{array}$ & $8(24.2)$ & $25(75.8)$ & 33 & 14.413 & 0.025 \\
\hline
\end{tabular}

ACTH, adrenocorticotropic hormone; $\mathrm{FHS} / \mathrm{LH}$, follicle-stimulating hormone/luteotropic hormone; GH, growth hormone; NULL, null cell; $\mathrm{PRL}$, prolactin; $\mathrm{TSH}$, thyroid-stimulating hormone.

expression of HIF- $1 \alpha$ between cystic adenomas and noncystic adenomas, and the high expression of GLUT3 in cystic adenomas was consistent with this HIF- $1 \alpha$ expression pattern. We thus speculate that the blood supply to these PAs was insufficient, and the tumor cells were susceptible to ischemia and hypoxia, which in turn makes PAs susceptible to cystic changes.

Thus far, the role of GLUT3 in tumor cystic changes has not been reported, but other studies have shown that ischemia-hypoxia plays an important role in the occurrence and development of cystic changes, especially in terms of the expression of HIF-1 induced by ischemia and hypoxia in renal cysts. Nag et al. found that stabilized HIF-1 $\alpha$ alters both transcellular and paracellular transport through renal epithelial monolayers in a manner consistent with secretory behavior, indicating that localized ischemia-hypoxia of the normal epithelium near the cyst leads to a change in transepithelial transport, thereby promoting cyst expansion (14).

The high metabolic growth of PAs results in tumor tissues being in an ischemic and hypoxic state and, thus, prone to changes in ischemia, necrosis and cystic change (15). PAs are susceptible to bleeding and cystic change for two main reasons $(16,17)$. First, PAs are overgrown, so nutrient-providing blood vessels are subject to pressure that can result in ischemia, necrosis and secondary hemorrhage. Second, other factors, such as trauma, radiotherapy, hormone-level disorders, bromocriptine therapy, anticoagulation and intracranial pressure fluctuations, can also contribute to this phenomenon. There are currently two main hypotheses for the development of cystic change in PA $(18,19)$ : the first hypothesis is that it is caused by ischemia and necrosis of adenoma tissue and the second is that it is secondary to intratumoral hemorrhage. Both hypotheses are concordant in that cystic change of PA is related to an insufficient blood supply. In addition, cystic change in PAs often occurs more than once. The most common explanation is that recurrent, small-scale infarct hemorrhaging in adenoma tissue occurs, and, after a hematoma is absorbed, a cyst forms. The presence of sponge-like or spot-like signs in PAs identified using MRI may be a prelude to multiple cystic changes (20).

Our findings indicated that the expression of GLUT3 in cystic change adenomas is higher than that found in solid adenomas. Tumor cells upregulate the expression of GLUT3 to satisfy changes in ischemia and hypoxia. Previous studies have shown that PAs with large volumes and rapid growth are more prone to hemorrhaging and cystic change (21). Our results indicate that there is a difference in GLUT3 expression between microadenomas, macroadenomas and giant adenomas, in which the larger the diameter of the tumor, the greater the likelihood of ischemia, hypoxia and secondary cystic change.

Among the different hormone types of PA, some studies have suggested that PRL adenomas are the most susceptible to cystic change. It has been reported that functional PAs are prone to tumor ischemia and stroke because of their high metabolisms (22). A study of HIF$1 \alpha$ has shown that the oxygen consumption of PRL adenomas is higher than that of other hormone types of Pas (23), indicating that PRL adenomas are more predisposed to ischemia and hypoxia. In the current

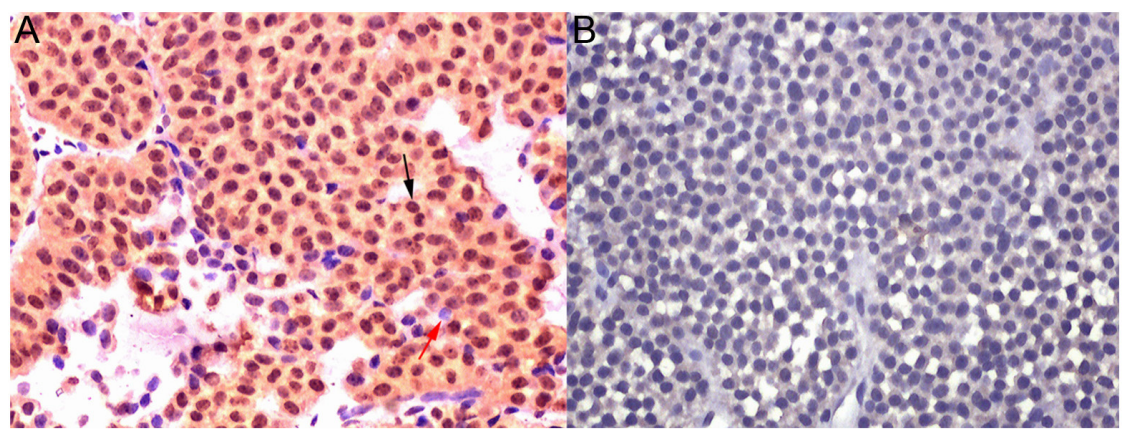

\section{Figure 6}

Expression of HIF-1 $\alpha$ in pituitary adenoma cells (A, 200x, black arrows). A small number of cells are negative (red arrows). HIF-1 $\alpha$-negative immunostaining in pituitary adenoma cells (B, 200x). https://ec.bioscientifica.com

https://doi.org/10.1530/EC-18-0444 (c) 2018 The authors Published by Bioscientifica Ltd

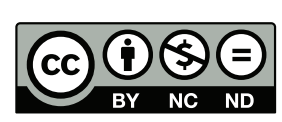

This work is licensed under a Creative Commons Attribution-NonCommercial-NoDerivatives 4.0 International License. 
Table 6 Expression of HIF-1 $\alpha$ in pituitary adenomas.

\begin{tabular}{|c|c|c|c|c|c|}
\hline \multirow[b]{2}{*}{ Cystic change } & \multicolumn{2}{|c|}{ HIF-1 $\alpha(\%)$} & \multirow[b]{2}{*}{$n$} & \multirow[b]{2}{*}{$\chi^{2}$} & \multirow[b]{2}{*}{$P$} \\
\hline & Negative & Positive & & & \\
\hline No & $15(68.2)$ & $7(31.8)$ & 22 & & \\
\hline Yes & $10(35.7)$ & $18(64.3)$ & 28 & 5.195 & 0.023 \\
\hline
\end{tabular}

study, we observed the highest GLUT3 expression in cases of PRL adenoma, with expression mainly in the cell membrane. We speculate that this localization is related to its strong functional role in glucose metabolism and may be associated with the increased susceptibility to ischemia of PRL adenomas compared to that of other types of PA.

Interestingly, we observed paranuclear dot-like GLUT3 staining in FSH/LH adenomas. Paranuclear dotlike positivity is not common and is considered to reflect Golgi accentuation of cytoplasmic immunolabeling. Most findings in the current literature regarding paranuclear dot-like staining focus on CD99 expression (24). The main function of the Golgi apparatus is to process and package protein synthesized by the endoplasmic reticulum, followed by transport to a specific part of the cell. We hereby propose the term 'reserve cells' to indicate those cells with positive paranuclear dot-like staining under ischemic and hypoxic conditions that nonetheless fail to attain a high-energy metabolic state as a result of GLUT3 cell membrane expression. Our findings support the notion that PRL adenomas are more prone to ischemia, hypoxia and secondary cystic change. Furthermore, the metabolism of FSH/LH adenoma cells appears to be less efficient than that of PRL adenoma cells, although FSH/LH adenoma cells are still susceptible to ischemia and hypoxia. Cases of FSH and null-cell PA are more common in clinical practice, with patients frequently exhibiting no symptoms or atypical symptoms in the early stage. Thus, by the time treatment starts, these tumors tend to be large and may readily compress blood vessels near the diaphragma sellae, resulting in tumor ischemic cystic change.

A recent study demonstrated the presence of vasculogenic mimicry (VM) in a series of surgically resected clinically non-functioning Pas (25). VM refers to the phenomenon in which vascular-like channels, which are lined by tumor cells and not endothelial cells, are formed in tumors. VM has been proposed as an additional mechanism for neoplastic blood perfusion. Findings thus suggest the existence of a complementary perfusion system in PAs. Since vascularization is low in PAs, VM could create a collateral perfusion path for maintaining adequate blood supply to the tumor. In this regard, VM would complement the existing vascular system, providing pituitary tumor cells with an alternate mode

https://ec.bioscientifica.com

https://doi.org/10.1530/EC-18-0444 (c) 2018 The authors Published by Bioscientifica Ltd of survival (25). The presence of VM was not observed in our specimens, probably because we did not use CD34 and Periodic Acid-Schiff (PAS) double staining. However, we did observe higher GLUT3 expression in clinically non-functioning PAs, including null-cell adenomas and most FSH/LH adenomas with normal serum hormones. Thus, the existence of VM complements our findings. We hypothesize that VM and GLUT3 may play important roles in different growth stages of pituitary tumors, complementing each other and promoting tolerance to hypoxia-ischemia in PAs at different stages. Our study shows that the expression of GLUT3 differs among PA types, indicating that the degrees of ischemia and hypoxia differ among PA types as well. In addition to increasing the blood supply to take in more oxygen, the cells are also able to acquire additional energy through the upregulation of GLUT3.

\section{Conclusions}

We discovered that the expression patterns of GLUT3 differed among various PA hormone types, which may indicate differences in metabolism among these PA types. Since PAs are characterized by an insufficient blood supply, PA tumor cells may be vulnerable to ischemia and hypoxia, which may lead to cystic changes.

\section{Declaration of interest}

The authors declare that there is no conflict of interest that could be perceived as prejudicing the impartiality of the research reported.

\section{Funding}

This work was supported by the Natural Science Foundation of Fujian Province of China (grant number 2018Y0067) and the Fuzhou General Hospital Innovation Team Fund (project number 2014CXTD07).

\section{Acknowledgements}

The authors thank Meishan Dai for assistance with the immunohistochemical methods and valuable discussion.

\section{References}

1 Raappana A, Koivukangas J, Ebeling T \& Pirilä T. Incidence of pituitary adenomas in Northern Finland in 1992-2007. Journal of Clinical Endocrinology and Metabolism 201095 4268-4275. (https:// doi.org/10.1210/jc.2010-0537)

2 Ryu SI, Tafti BA \& Skirboll SL. Pituitary adenomas can appear as hypermetabolic lesions in 18F-FDG PET imaging. Journal of Neuroimaging 201020 393-396. (https://doi.org/10.1111/j.15526569.2008.00347.x)

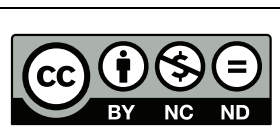
This work is licensed under a Creative Commons
Attribution-NonCommercial-NoDerivatives 4.0 International License. 
3 Kristof RA, Aliashkevich AF, Hans V, Haun D, Meyer B, Thees C \& Schramm J. The regional oxygen saturation of pituitary adenomas is lower than that of the pituitary gland: microspectrophotometric study with potential clinical implications. Neurosurgery $2003 \mathbf{5 3}$ 880-885. (https://doi.org/10.1227/01.NEU.0000083604.09901.F6)

4 Szablewski L. Glucose transporters in brain: in health and in Alzheimer's disease. Journal of Alzheimers Disease 201755 1307-1320. (https://doi.org/10.3233/JAD-160841)

5 Jurcovicova J. Glucose transport in brain - effect of inflammation. Endocrine Regulations 201448 35-48. (https://doi.org/10.4149/ endo_2014_01_35)

6 Fung C, Evans E, Shin D, Shin BC, Zhao Y, Sankar R, Chaudhuri G \& Devaskar SU. Hypoxic-ischemic brain injury exacerbates neuronal apoptosis and precipitates spontaneous seizures in glucose transporter isoform 3 heterozygous null mice. Journal of Neuroscience Research 201088 3386-3398. (https://doi.org/10.1002/ jnr.22487)

7 Barron CC, Bilan PJ, Tsakiridis T \& Tsiani E. Facilitative glucose transporters: implications for cancer detection, prognosis and treatment. Metabolism Clinical and Experimental 201665 124-139. (https://doi.org/10.1016/j.metabol.2015.10.007)

8 Huang Y, Lei L, Liu D, Jovin I, Russell R, Johnson RS, Di Lorenzo A \& Giordano FJ. Normal glucose uptake in the brain and heart requires an endothelial cell-specific HIF- $1 \alpha$-dependent function. PNAS 2012109 17478-17483. (https://doi.org/10.1073/ pnas.1209281109)

9 Han X, Sun S, Zhao M, Cheng X, Chen G, Lin S, Guan Y \& Yu X. Celastrol stimulates hypoxia-inducible factor-1 activity in tumor cells by initiating the ROS/Akt/p70S6K signaling pathway and enhancing hypoxia-inducible factor-1 $\alpha$ protein synthesis. PLOS ONE 20149 e112470. (https://doi.org/10.1371/journal.pone.0112470)

10 Kremer JC, Prudner BC, Lange SES, Bean GR, Schultze MB, Brashears CB, Radyk MD, Redlich N, Tzeng SC, Kami K, et al. Arginine deprivation inhibits the warburg effect and upregulates glutamine anaplerosis and serine biosynthesis in ASS1-deficient cancers. Cell Reports 201718 991-1004. (https://doi.org/10.1016/j. celrep.2016.12.077)

11 Fenske W, Völker HU, Adam P, Hahner S, Johanssen S, Wortmann S, Schmidt M, Morcos M, Müller-Hermelink HK, Allolio B, et al. Glucose transporter GLUT1 expression is an stage-independent predictor of clinical outcome in adrenocortical carcinoma. Endocrine-Related Cancer 200916 919-928. (https://doi.org/10.1677/ERC-08-0211)

12 Mattern J, Koomägi R \& Volm M. Biological characterization of subgroups of squamous cell lung carcinomas. Clinical Cancer Research 19995 1459-1463.

13 Trouillas J, Roy P, Sturm N, Dantony E, Cortet-Rudelli C, Viennet G, Bonneville JF, Assaker R, Auger C, Brue T, et al. A new prognostic clinicopathological classification of pituitary adenomas: a multicentric case-control study of 410 patients with 8 years postoperative follow-up. Acta Neuropathologica 2013126 123-135. (https://doi.org/10.1007/s00401-013-1084-y)
14 Nag S \& Resnick A. Stabilization of hypoxia inducible factor by cobalt chloride can alter renal epithelial transport. Physiological Reports 20175 e13531. (https://doi.org/10.14814/phy2.13531)

15 Kristof RA, Aliashkevich AF, Hans V, Haun D, Meyer B, Thees C \& Schramm J. The regional oxygen saturation of pituitary adenomas is lower than that of the pituitary gland: microspectrophotometric study with potential clinical implications. Neurosurgery $2003 \mathbf{5 3}$ 880-885. (https://doi.org/10.1227/01.NEU.0000083604.09901.F6)

16 Kim DJ, Song YJ, Kim SJ, Park MK, Choi SS \& Kim KU. Pituitary hemorrhage: classification and related factors. Journal of Korean Neurosurgical Society 200946 23-30. (https://doi.org/10.3340/ jkns.2009.46.1.23)

17 Elsässer Imboden PN, De Tribolet N, Lobrinus A, Gaillard RC, Portmann L, Pralong F \& Gomez F. Apoplexy in pituitary macroadenoma: eight patients presenting in 12 months. Medicine 200584 188-196. (https://doi.org/10.1097/01. md.0000164205.77287.9e)

18 Semple PL, Jane JA, Lopes MB \& Laws ER. Pituitary apoplexy: correlation between magnetic resonance imaging and histopathological results. Journal of Neurosurgery $2008 \mathbf{1 0 8} 909$. (https://doi.org/10.3171/JNS/2008/108/5/0909)

19 Zhang J, Gu J, Ma Y, Huang Y, Wang J, Wu Z, Zhong Q \& Wang S. Uneven distribution of regional blood supply prompts the cystic change of pituitary adenoma. World Neurosurgery 2017103 37-44. (https://doi.org/10.1016/j.wneu.2017.03.109)

20 Cazabat L, Dupuy M, Boulin A, Bernier M, Baussart B, Foubert L, Raffin-Sanson ML, Caron P, Bertherat J \& Gaillard S. Silent, but not unseen: multimicrocystic aspect on T2-weighted MRI in silent corticotroph adenomas. Clinical Endocrinology 201481 566-572. (https://doi.org/10.1111/cen.12443)

21 Möller-Goede DL, Brändle M, Landau K, Bernays RL \& Schmid C. Pituitary apoplexy: re-evaluation of risk factors for bleeding into pituitary adenomas and impact on outcome. European Journal of Endocrinology 2011164 37-43. (https://doi.org/10.1530/EJE-10-0651)

22 Liu ZH, Chang CN, Pai PC, Wei KC, Jung SM, Chen NY \& Chuang CC. Clinical features and surgical outcome of clinical and subclinical pituitary apoplexy. Journal of Clinical Neuroscience 201017 694-699. (https://doi.org/10.1016/j.jocn.2009.11.012)

23 Yoshida D, Kim K, Yamazaki M \& Teramoto A. Expression of hypoxiainducible factor 1alpha and cathepsin D in pituitary adenomas. Endocrine Pathology 200516 123-131. (https://doi.org/10.1385/ EP:16:2:123)

24 Guo Y, Yuan F, Deng H, Wang HF, Jin XL \& Xiao JC. Paranuclear dot-like immunostaining for CD99: a unique staining pattern for diagnosing solid-pseudopapillary neoplasm of the pancreas. American Journal of Surgical Pathology 201135 799-806. (https://doi. org/10.1097/PAS.0b013e318219c036)

25 Di Michele J, Rotondo F, Kovacs K, Syro LV, Yousef GM, Cusimano MD \& Di Ieva A. Vasculogenic mimicry in clinically nonfunctioning pituitary adenomas: a histologic study. Pathology Oncology Research 201723 1-7. (https://doi.org/10.1007/s12253-016-0101-6)

Received in final form 23 November 2018

Accepted 6 December 2018

Accepted Preprint published online 6 December 2018 https://ec.bioscientifica.com https://doi.org/10.1530/EC-18-0444 (c) 2018 The authors Published by Bioscientifica Ltd

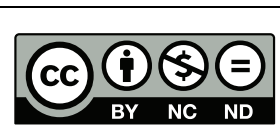

This work is licensed under a Creative Commons Attribution-NonCommercial-NoDerivatives 4.0 International License. 